\title{
Aspek matematis dalam tradisi nugal masyarakat Suku Dayak Sebaruk Daerah Jentawang, Ketungau Hilir, Kalimantan Barat
}

\author{
Mariani Dian* \\ Fakultas Keguruan dan Ilmu Pendidikan, Universitas Katolik Widya Mandala Surabaya. \\ * Corresponding Author. E-mail: marianidian6@gmail.com
}

Submitted: 30 November 2020 | Revised: 30 Maret 2021 | Accepted: 30 Maret 2021 | Available Online: 12 April 2021

\begin{abstract}
Abstrak
Nugal adalah tradisi yang dilakukan oleh Suku Dayak secara turun temurun. Nugal dilakukan oleh masyarakat Suku Dayak, saat pemilik lahan sudah membuka lahannya untuk berladang. Penelitian ini bertujuan untuk menggali aspek-aspek matematis yang terdapat pada proses nugal, maupun ritual adat yang dilakukan ketika hendak nugal. Ritual yang dilakukan disetiap daerah mungkin saja berbeda-beda. Oleh sebab itu peneliti membatasi ruang lingkup penelitian pada tradisi nugal yang dilakukan oleh masyarakat Suku Dayak Sebaruk, yang tinggal di Kampung Jentawang, Ketungau Hilir, Kalimantan Barat. Jenis penelitian yang digunakan adalah penelitian deskriptif kualitatif. Pada penelitian ini, akan dijelaskan proses-proses nugal, mulai dari ritual hingga pelaksanaannya. Proses pengumpulan data dilakukan dengan menggunakan wawancara terstruktur kepada masyarakat setempat, terkait dengan pelaksanaan tradisi ini. Analisis dilakukan melalui reduksi data sehingga diperoleh rangkaian kegiatan yang dilakukan pada tradisi nugal serta aspek matematis yang tampak di dalamnya. Hasil dari penelitian ini, baik pada ritual dan proses nugal itu sendiri, dapat ditemukan beberapa aspek matematis seperti beberapa contoh pernyataan logika serta pola-pola yang dapat digunakan untuk menuju konsep barisan dan deret. Selain itu terdapat pula unsur geometri pada pola-pola ini, sehingga dapat digunakan untuk mengantarkan pada konsep-konsep geometri seperti translasi, refleksi dan menghitung jarak antar titik.

Kata Kunci: Suku Dayak, tradisi nugal, matematika, geometri, logika
\end{abstract}

\section{Mathematical aspects in the nugal tradition of the Dayak Sebaruk Tribe, Jentawang Region, Ketungau Hilir, West Kalimantan}

\begin{abstract}
Nugal is a tradition carried out by Dayak Tribe from generation to generation. Generally, nugal was done together with the community where the landlord is staying, after the landlord cleared the land for farming. This study aims to explore the mathematical aspects seen in the nugal process and the rituals before the process of nugal. The rituals performed in each region may be different. Therefore, the study is limited to the nugal tradition carried out by the Dayak Sebaruk Tribe, who live in Jentawang Village, Ketungau Hilir, West Kalimantan. The research is a descriptive qualitative research, where the tradition will be explained, from the ritual to the method used in the process of nugal itself. The data collected using the systematic interview related to the implementation of this tradition in the community. Analysis of the data collection carried out using data reduction so that it is obtained a series of activities conducted in nugal and the mathematics aspects that appear in it. The results of this study were either in the ritual and the process of nugal, the mathematics aspects like logic statements and patterns that could be used for bringing the students to the sequences and series concept, was found. The patterns could also be used to bring the students to understanding geometric concepts like translation, reflection, and determining the distance of two points.
\end{abstract}

Keywords: Dayak people, mathematics, nugal tradition, geometry, logic

How to cite:

Dian, M. (2021). Aspek matematis dalam tradisi nugal masyarakat Suku Dayak Sebaruk Daerah Jentawang, Ketungau Hilir, Kalimantan Barat. Ethnomathematics Journal, 2(1), 38-42. https://doi.org/10.21831/ej.v2i1.35870

This is an open access article under the CC-BY-SA license. 


\section{PENDAHULUAN}

Matematika adalah pelajaran wajib yang diajarkan pada pendidikan formal, mulai dari tingkat dasar hingga menengah atas, bahkan sampai pada tingkatan perguruan tinggi. Hal ini membuktikan bahwa matematika merupakan hal yang penting dalam kehidupan (Katsap \& Silverman, 2008). Menurut Freudenthal (2002) matematika adalah aktivitas manusia sehingga dapat terintegrasi dalam aktivitas kehidupan sehari-hari. Akan tetapi, pada kenyataannya alasan kenapa matematika dianggap sebagai bagian yang terpisah dari kehidupan dan budaya dimulai dari ketidakmampuan seseorang menggunakan matematika sebagai alat untuk memecahkan permasalahan sehari-hari (Karnilah, 2013). Proses pembelajaran matematika yang jauh dari kehidupan sehari-hari akhirnya membuat matematika seolah-olah lepas dari budaya dan memberikan pengaruh pada kemampuan peserta didik dalam memecahkan masalah matematis yang didasarkan pada kehidupan sehari-hari (Muhtadi, Sukirwan, Warsito, \& Prahmana, 2017). Untuk melihat kembali hubungan antara matematika dan budaya, maka digunakanlah pendekatan matematika yang menggunakan budaya atau etnomatematika.

Etnomatematika berfokus pada relasi diantara matematika dan budaya (Albanese \& Perales, 2015). Etnomatematika diperkenalkan pertama kali oleh edukator dan matematikawan D'Ambrosio pada suatu presentasi untuk American Association for the Advancement of Science (Abdullah, 2017). Pada tahun 1984, D'Ambrosio juga menyarankan agar pendidikan matematika mencakup akar budayanya, menyatakan kembali proses budaya yang esensial dari teknik melakukan, menjelaskan, dan memahami tentang lingkungan alami dan sosial (Barton, 2016). Etnomatematika menjadikan budaya lokal sebagai suatu titik awal untuk pembelajaran matematika (Widada, Herawaty, \& Lubis, 2018). Hal-hal yang dipelajari dalam etnomatematika meliputi simbol-simbol, konsep-konsep, prinsip-prinsip, dan kemampuan matematis yang ada dalam komunitas nasional, suku atau komunitas-komunitas lainnya (Abdullah, 2017). Salah satu budaya lokal yang dapat dijadikan sumber sebagai media untuk menggali aspek matematis adalah tradisi nugal yang dilakukan oleh masyarakat Suku Dayak.

Tradisi nugal merupakan bagian dari kebudayaan Suku Dayak. Nugal adalah tradisi menanam padi secara bersama-sama. Biasanya pemilik lahan akan mengajak sanak saudara dan tetangganya untuk menanam padi secara bersamaan. Tradisi ini dapat berbeda disetiap daerah, tergantung pada lingkungan tempat mereka tinggal. Satu hal yang menjadi ciri khas dari kebudayaan ini, adalah nilai kebersamaan dan gotong royong sangat diutamakan. Pada saat ini, tradisi nugal sudah mulai jarang dilakukan, walaupun pada beberapa daerah masih tetap dilakukan. Faktor yang cukup penting dalam menjalankan tradisi ini adalah ketersediaan lahan. Berdasarkan penjabaran-penjabaran yang sudah diuraikan tersebut, maka artikel ini akan mendiskusikan tentang aspek-aspek matematis yang terdapat dalam tradisi nugal yang dilakukan oleh masyarakat Suku Dayak Sebaruk di Kampung Jentawang, Ketungau Hilir, Kalimantan Barat.

\section{METODE}

Jenis penelitian ini adalah penelitian deskriptif kualitatif, yang menjelaskan data secara keseluruhan, ekstensif dan mendalam (Prahmana, Kusumah, \& Darhim, 2017). Proses pengumpulan data dilakukan dengan cara wawancara kepada masyarakat Suku Dayak setempat yang juga pernah terlibat dalam menjalankan tradisi nugal. Wawancara merupakan proses komunikasi dan interaksi antara pewawancara dan narasumber melalui komunikasi langsung (Yusuf, 2017). Dalam penelitian ini, wawancara yang dilakukan adalah wawancara terstruktur terkait dengan ritual dan langkahlangkah yang dilakukan pada saat proses tradisi nugal berlangsung, khususnya tradisi pada Suku Dayak Sebaruk yang tinggal di Jentawang, Ketungau Hilir, Kalimantan Barat. Data yang sudah diperoleh kemudian dianalisis dengan cara mereduksi data, sehingga diperoleh data yang sesuai dengan rumusan masalah yang diberikan. 


\section{HASIL DAN PEMBAHASAN}

Pada proses tradisi nugal biasanya dilakukan setelah proses pembakaran lahan, yang oleh masyarakat setempat disebut sebagai proses bakar ladang (proses pembakaran ini melalui tahapantahapan dan kondisi tertentu). Nugal dilakukan dua atau tiga hari setelah lahan dibakar. Mula-mula, pemilik lahan membawa bibit-bibit padi yang paling baik ke lahan. Bibit-bibit padi tersebut dibawa menggunakan tempat yang disebut temungan, yang dipercaya bahwa jiwa atau semangat padi tersimpan dalam temungan itu. Bibit padi dibawa pagi-pagi, menjelang matahari terbit. Masyarakat percaya bahwa membawa bibit padi ke lahan menjelang matahari terbit akan memberikan rezeki yang semakin baik pula, seiring dengan matahari yang semakin naik. Selain bibit padi, tanamantanaman lain seperti tanaman tuba juga dibawa ke lahan tersebut, dengan tujuan untuk mengusir rohroh jahat yang hendak merusak jiwa padi, seperti penyakit dan hama.

Sebelum bibit padi ditugal (ditanam ke dalam lubang yang dibuat dengan menancapakan kayu), biasanya diolesi dengan darah ayam atau telur ayam dengan tujuan untuk menguatkan roh atau jiwa padi tersebut. Darah ayam atau telur juga dioleskan pada lahan dengan tujuan untuk mengusir roh-roh jahat dilahan tersebut sehingga padi dapat berkembang dengan baik. Selain menggunakan ayam dan telur, masyarakat dengan tingkat ekonomi yang baik juga terkadang menggunakan darah babi atau ayam dalam jumlah yang lebih besar, kemudian dagingnya dimakan bersama-sama dengan warga lain yang ikut terlibat. Setelah bibit-bibit utama tersebut ditugal barulah proses nugal dilakukan bersama masyarakat. Proses nugal bersama masyarakat biasanya dilakukan pada hari yang sama setelah bibit utama ditugal atau satu sampai dua hari setelahnya.

Pada prosesnya, ada kelompok yang melubangi tanah menggunakan kayu runcing (proses nugal) dan kelompok yang menaburkan benih, di belakang kelompok yang nugal. Jarak antar lubang yang dibuat umumnya seruas tulang tangan orang dewasa (dari siku sampai pergelangan tangan). Kelompok yang nugal akan berjalan ke depan sambil menusuk tanah di depan dan di samping kanan kirinya. Kelompok yang menabur benih mengikuti di belakang kelompok yang nugal.

Beberapa aspek matematis dapat ditemukan, mulai dari ritual sebelum tradisi nugal hingga proses tradisi nugal itu sendiri dilakukan. Pertama-tama, yang tampak adalah adanya hubungan sebab akibat. Beberapa contoh yang dapat kita ambil misalnya: (1) Jika bibit padi yang paling baik dibawa ke ladang (lahan) menjelang matahari terbit, maka dipercaya bibit padi akan membawakan rezeki yang semakin baik pula. (2) Jika tanah yang akan ditugal diolesi oleh darah ayam atau telur, maka dipercaya padi dapat berkembang dengan baik. (3) Jika padi diolesi dengan darah ayam atau telur, maka dipercaya jiwa padi akan semakin kuat. Selanjutnya ada pula pernyataan yang merupakan contoh dari pernyataan disjungsi, yaitu bibit padi yang akan ditugal diolesi dengan darah ayam atau telur.

Apabila kita melihat pada proses nugal, pengukuran yang dilakukan oleh masyarakat ketika mengambil jarak antar lubang tugal cukup sederhana, dengan menggunakan ruas tulang tangan. Kelebihan proses pengukuran ini adalah praktis dan sederhana, sehingga tidak memakan waktu yang lama. Kelemahannya adalah pengukuran ini cenderung tidak konsisten karena bagian siku sampai lengan seseorang juga akan bergerak ketika mengangkat kayu untuk melubangi tanah, belum lagi ditambah dengan kontur tanah yang tidak selalu datar. Jika diasumsikan bahwa ukurannya tetap dan lahan tempat nugal memiliki kontur datar, maka dapat diperoleh pola seperti pada Gambar 1.

Pada Gambar 1 dapat dilihat bahwa titik-titik merah merupakan lubang tugal yang sudah dibuat seseorang. Lubang tugal tersebut selanjutnya dapat direpresentasikan sebagai suatu pola yang dapat digunakan untuk tujuan memperkenalkan suatu konsep. Pola tersebut dapat digunakan menghitung seberapa banyak lubang tugal yang dibuat sampai pada suatu jarak tertentu, yang selanjutnya dapat digunakan untuk memperkenalkan konsep perkalian. Contohnya, karena pada setiap langkah seseorang membuat tiga lubang tugal, maka setelah $n$ langkah akan ada $\underbrace{3+3+3+\cdots+3}$ lubang tugal, atau akan diperoleh bentuk $n \times 3$. Berangkat dari pola ini pula sebanyak $n$ kali maka akan terbentuk konsep baris, dimana baris yang terbentuk adalah suatu baris konstana $U_{n}=$ $3,3,3,3, \ldots$. Selain konsep baris dan deret, pola-pola yang terbentuk tersebut juga mengandung unsur-unsur geometri, sehingga dapat digunakan untuk menyampaikan konsep-konsep geometri seperti translasi dan refleksi, serta jarak antar titik. 


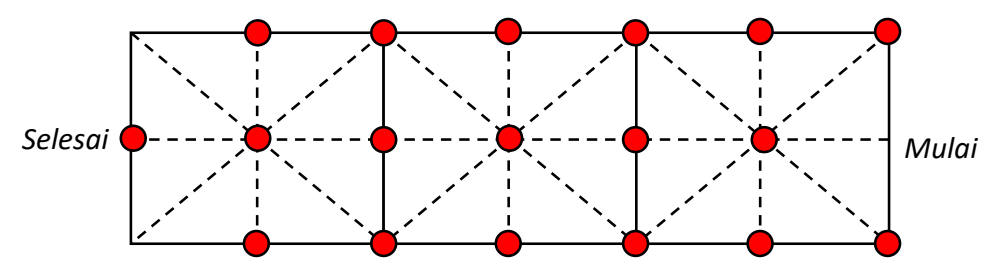

Gambar 1. Pola untuk membuat lubang pada tanah.

\section{SIMPULAN}

Berdasarkan hasil dan pembahasan yang diperolah dalam penelitian ini adalah bahwa pada tradisi nugal ditemukan aspek-aspek matematis, baik yang berkaitan dengan bahasa-bahasa logika matematika maupun pola-pola yang digunakan masyarakat untuk menghitung atau mengukur jarak lubang tanam. Hal ini menunjukkan bahwa secara tidak langsung tradisi masyarakat memiliki kaitan baik secara eksplisit dan implisit dengan beberapa konsep matematis. Aspek matematis yang digali pada ritual dan proses tradisi nugal masih terbatas pada aspek-aspek yang mudah diamati dan dikaitkan dengan konsep perkalian, baris bahkan geometri. Bagi peneliti lainnya yang ingin menggali lebih dalam tentang aspek matematis dalam tradisi ini, dapat mengarahkan fokus penelitian pada hal lain, seperti meneliti aspek matematis pada objek-objek yang digunakan seperti pada temungan atau meneliti lebih lanjut proses nugal dan ritualnya untuk menemukan aspek matematis lainnya.

\section{DAFTAR PUSTAKA}

Abdullah, A. S. (2017). Ethnomathematics in perspective of sundanese culture. Journal on Mathematics Education, 8(1), 1-16. Retrieved from https://files.eric.ed.gov/fulltext/EJ1173644.pdf

Albanese, V., \& Perales, F. J. (2015). Enculturation with ethnomathematical microprojects: From culture to mathematics. Journal of Mathematics \& Culture, 9(1). Retrieved from https://journalofmathematicsandculture.files.wordpress.com/2016/05/albanese-and-perales91.pdf

Barton, B. (2016). Mathematics, education, and culture: A contemporary moral imperative. In G. Kaiser (Ed.), Proceedings of the 13th International Congress on Mathematical Education. Retrieved from https://link.springer.com/content/pdf/10.1007\%2F978-3-319-62597-3_3.pdf

Freudenthal, H. (2002). Revisiting mathematics education: China lectures. New York: KluwerAcademic Publishers.

Karnilah, N. (2013). Study ethnomathematics: Pengungkapan sistem bilangan masyarakat adat Baduy. Universitas Pendidikan Indonesia.

Katsap, A., \& Silverman, F. L. (2008). A case study of the role of ethnomathematics among teacher education students from highly diverse cultural backgrounds. The Journal of Mathematics and Culture, 3(1), 66-102. $\quad$ Retrieved from https://journalofmathematicsandculture.files.wordpress.com/2016/05/the-role-ofethnomathematics.pdf

Muhtadi, D., Sukirwan, S., Warsito, W., \& Prahmana, R. C. I. (2017). Sundanese ethnomathematics: Mathematical activities in estimating, measuring, and making patterns. Journal on Mathematics Education, 8(2), 185-198. https://doi.org/10.22342/jme.8.2.4055.185-198

Prahmana, R. C. I., Kusumah, Y. S., \& Darhim, D. (2017). Didactic trajectory of research in mathematicseducation using research-based learning. Journal of Physics: Conference Series, 893(1), 012001. https://doi.org//10.1088/1742-6596/893/1/012001

Widada, W., Herawaty, D., \& Lubis, A. N. M. T. (2018). Realistic mathematics learning based on 
theethnomathematics in Bengkulu to improvestudents' cognitive level. Journal of Physics: Conference Series, 1088(1), 012028. https://doi.org/10.1088/1742-6596/1088/1/012028

Yusuf, M. (2017). Metode penelitian kuantitatif, kualitatif \& penelitian gabungan (4th ed.). Jakarta: Kencana. 